\title{
Erratum to: Efficacy and Safety Study of Olmesartan Medoxomil, Amlodipine, and Hydrochlorothiazide Combination Therapy in Patients with Hypertension Not Controlled with Olmesartan Medoxomil and Hydrochlorothiazide Combination Therapy: Results of a Randomized, Double-Blind, Multicenter Trial
}

\author{
Il Suk Sohn ${ }^{1}$ Chong-Jin Kim ${ }^{1} \cdot$ Byung-Hee $\mathrm{Oh}^{2} \cdot$ Taek-Jong Hong ${ }^{3}$. \\ Chang-Gyu Park ${ }^{4}$ Byung-Soo $\mathrm{Kim}^{5} \cdot$ Woo-Baek Chung ${ }^{6} \cdot$ For the Investigators \\ Published online: 18 March 2016 \\ (C) Springer International Publishing Switzerland 2016
}

\section{Erratum to: Am J Cardiovasc Drugs DOI 10.1007/s40256-015-0156-x}

Errors have subsequently been identified in the original publication, and the following corrections should be noted:

Abstract, Results section, lines 9-11 which previously read:

After 8 weeks of double-blind treatment, the changes in $\mathrm{msDBP}$ were $-9.50(8.46) \mathrm{mmHg}$ in the OM/AML/HCTZ group and $-4.23(7.41) \mathrm{mmHg}$ in the $\mathrm{OM} / \mathrm{HCTZ}$ group (both $p<0.0001$ vs. baseline; $p<0.0001$ between groups).

Should read:

After 8 weeks of double-blind treatment, the changes in msDBP were $-11.39(8.34) \mathrm{mmHg}$ in the OM/AML/ HCTZ group and $-5.74(9.22) \mathrm{mmHg}$ in the OM/HCTZ

The online version of the original article can be found under doi:10. 1007/s40256-015-0156-x.

Byung-Hee Oh

ohbhmed@snu.ac.kr

1 Kyung Hee University Hospital at Gangdong, Seoul, Republic of Korea

2 Division of Cardiology, Department of Internal Medicine, Seoul National University College of Medicine, Seoul National University Hospital, 101 Daehak-ro(28 Yongondong), Jongno-gu, Seoul 110-744, Republic of Korea

3 Pusan National University Hospital, Busan, Republic of Korea

4 Korea University Guro Hospital, Seoul, Republic of Korea

5 Daedong Hospital, Busan, Republic of Korea

6 Yeouido St. Mary's Hospital of the Catholic University of Korea, Seoul, Republic of Korea group (both $p<0.0001$ vs. baseline; $p<0.0001$ between groups).

Results, Section 3.2 Efficacy, para 1, lines 2-3 which previously read:

After 8 weeks of double-blind treatment, the changes in msDBP were $-9.50(8.46) \mathrm{mmHg}$ in the OM/AML/HCTZ group and -4.23 (7.41) $\mathrm{mmHg}$ in the $\mathrm{OM} / \mathrm{HCTZ}$ group (both $p<0.0001$ vs. baseline; $p<0.0001$ between groups; Fig. 2a).

Should read:

After 8 weeks of double-blind treatment, the changes in msDBP were -11.39 (8.34) $\mathrm{mmHg}$ in the OM/AML/ HCTZ group and $-5.74(9.22) \mathrm{mmHg}$ in the $\mathrm{OM} / \mathrm{HCTZ}$ group (both $p<0.0001$ vs. baseline; $p<0.0001$ between groups; Fig. 2a).

Results, Section 3.2 Efficacy, para 2, lines 2-5 which previously read:

The changes in msDBP and msSBP from randomization to after 4 weeks of treatment were $-11.39(8.34) \mathrm{mmHg}$ and -14.75 (12.50) $\mathrm{mmHg}$, respectively, in the OM/AML/ HCTZ group (both $p<0.0001$ vs. baseline) and -5.74 (9.22) $\mathrm{mmHg}$ and -7.93 (11.99) $\mathrm{mmHg}$, respectively, in the OM/HCTZ group (both $p<0.0001$ vs. baseline; both $p<0.0001$ between groups; Fig. 2).

Should read:

...The changes in msDBP and msSBP from randomization to after 4 weeks of treatment were $-9.50(8.46) \mathrm{mmHg}$ and -14.75 (12.50) $\mathrm{mmHg}$, respectively, in the OM/AML/ HCTZ group (both $p<0.0001$ vs. baseline) and -4.23 (7.41) $\mathrm{mmHg}$ and -7.93 (11.99) $\mathrm{mmHg}$, respectively, in the OM/HCTZ group (both $p<0.0001$ vs. baseline; both $p<0.0001$ between groups; Fig. 2). 